\title{
Cognate Effect and Lexical Processing in English-Spanish and Spanish-English Bilinguals
}

Meredith Jocelyn Jane MCGREGOR*

\begin{abstract}
Cognates have served as a useful tool for investigating the bilingual lexicon in many studies, but very little research has been carried out on different types of cognates, specifically, partial cognates and their role in cross-linguistic effect. The present study examines cognate effect in the speech production and acceptability judgment of two groups of highly proficient, late-onset English-Spanish $(n=12)$ and Spanish-English $(n=12)$ bilinguals within a single-language (English) context. The findings of two tasks, a production task, whereby participants were asked to spontaneously produce synonyms to prompt words, and an acceptability judgment task of a variety of sentences including use of false and partial EnglishSpanish cognates are reported here, framed within non-selective, integrated models of lexical representation. The results suggest a significant cognate effect in both bilingual groups in both tasks compared to their monolingual counterparts with, surprisingly, greater significance demonstrated from L2 to L1 influence, particularly in production. These findings add to the growing support for semantic modulation at the conceptual level of lexical processing in highly proficient bilinguals.
\end{abstract}

Keywords: bilingualism; cognate effect; lexical processing; Spanish; English.

University of Western Ontario, Ontario, Canada.

Corresponding author: mjmcgreg@uwo.ca

Received: 2015-11-25 / Sent for peer review: 2016-01-27 / Accepted by peers: 2016-04-12 / Approved: 2016-06-24 To reference this article in APA style / Para citar este artículo en APA / Para citar este artigo

Mcgregor, M. (2016). Cognate effect and lexical processing in English-Spanish and Spanish-English bilinguals. LACLIL, 9(1), 174-209. doi:10.5294/laclil.2016.9.1.8 


\section{El efecto de los cognados y el procesamiento léxico en hablantes bilingües de inglés-español y de español-inglés}

\section{Resumen}

El presente estudio examina el efecto de los cognados en la producción de un discurso y el juicio de aceptación de un grupo de 24 hablantes bilingües de inglés y español y de español e inglés con un alto nivel de manejo de ambas lenguas en un contexto donde se habla inglés únicamente. Los hallazgos de estas dos tareas se reportan aquí, y estas se enmarcan en modelos de representación léxica no selectiva. Los resultados sugieren un efecto significativo de los cognados en el grupo de participantes en las dos tareas en comparación con sus contrapartes monolingües. Sorpresivamente, se aprecia una gran significancia relacionada con la influencia de la segunda lengua en la primera lengua. Estos hallazgos apoyan la modulación semántica que a nivel conceptual del procesamiento léxico sucede en hablantes bilingües con altos niveles de manejo de las lenguas.

Palabras clave: bilingüismo; efecto de los cognados; procesamiento léxico; español. 


\section{O efeito dos cognatos e o processamento lexical em falantes bilíngues de inglês-espanhol e de espanhol-inglês}

\section{Resumo}

Este estudo analisa o efeito dos cognatos na produção de um discurso e o índice de aceitação de um grupo de 24 falantes bilíngues de inglês-espanhol e de espanhol-inglês com um alto nível de domínio de ambas as línguas num contexto em que se fala inglês unicamente. Os achados de duas tarefas são relatados aqui, as quais se delimitam em modelos de representação lexical não seletiva. Os resultados sugerem um efeito significativo dos cognatos no grupo de participantes nas duas tarefas em comparação com suas contrapartes monolíngues. Observase uma grande significância relacionada com a influência da segunda língua na primeira língua. Essas constatações apoiam a modulação semântica que, no âmbito conceitual do processamento lexical, se registra em falantes bilíngues com alto domínio das línguas.

Palavras-chave: bilinguismo; efeito dos cognatos; processamento lexical; espanhol. 


\section{INTRODUCTION}

Bilingual and multilingual individuals possess more than one set of lexical representations from which to draw upon when faced with the demands of speech production. As a result, there is always a cognate advantage in speech production and recognition in bilinguals (Sherkina, 2003). However, as "cognate status is a continuum" (Szubko-Sitarek, 2015, p. 136), cognitive processing in bilinguals/multilinguals poses interesting questions, especially regarding the conceptual level of lexical access (see Caramazza, 1997). Cognates are semantically, morphologically, phonologically (Amengual, 2012), pragmatically, and orthographically overlapping lexical items drawn from categorically different lexicons. They are words that tend to look, mean and sound the same in two or more languages, and they may even be spelled the same way. Examples of orthographically identical cognates in English and Spanish are animal, canal, and escape. Although they are pronounced differently (canal comes close: /kə'næl/ [English], and / ka'nal/ [Spanish], but is still not phonetically identical), on paper these words are the same, and, semantically, they are more or less equal as well. In its infinitive form in Spanish, escape diverges slightly as the reflexive verb escaparse, but it carries so many similarities to the English word that, even without a lot of context, one might be able to guess its meaning, as with abundancia, famoso, and religión, known as semi-cognates (de Bot, Cox, Ralston, Schaufeli, \& Weltens, 1995, p.4). And there are hundreds more examples like these. ${ }^{1}$ However, something interesting about cognates is that there is conceptual variation among them. False cognates (also known as false friends) are words that may look and sound the same but that do not function interchangeably as is the case in the word bigote-meaning moustache, not bigot, as one might suspect, or asistir - meaning attend, not assist. While identical and semi-cognates can be an asset to language learners, these false cognates can have the opposite effect.

1 Johnston's 1941 study, "Spanish-English Cognates of High Frequency", looked at the 3022 most frequent words in Spanish and the 3000 most frequent words in English and found one-third of them to be "related through Latin" and 50 others through other sources, mostly Germanic roots (p. 405). 
On the continuum between true cognates and false cognates exist partial cognates (Child, 2010). Partial cognates are lexical items that sometimes work like cognates and sometimes, deceptively, do not. An example of this is the Spanish noun convicción. It does mean conviction, as in a deeply held belief, but its definition does not carry over into the additional meaning a guilty verdict as it does in English. Likewise, the Spanish word banco means bank in English, as in the financial institution, but it also means bench. A Spanish speaker learning English would have to be careful with this "false friend", as referring to a park bench as a bank would cause confusion. A sub-category of partial cognates consists of those that, in spite of possessing non-cognate definitions that do not translate directly, might be used interchangeably among bilinguals without significant communication breakdown. Recall the reflexive verb cognate escaparse noted above. In English, to escape denotes a sense of fleeing from some form of captivity. In Spanish, the same is true, but this verb is also used to describe the act of skipping school or cutting out early from work. There is considerable semantic overlap, but the degree to which an individual might accept: She escaped early from work yesterday afternoon depends on one's linguistic repertoire. It might sound somewhat strange to a native English speaking monolingual, and the desired meaning may or may not be successfully conveyed. To another native English speaker who is proficient in Spanish, it might not seem so objectionable; it might not even be registered as unusual.

These partial cognates can cause what is known as cognate effect, which is when a non-target language plays a role in influencing a target language. Due to their relatedness across languages, cognates can affect language production and/or comprehension in bilinguals/multilinguals, but there are often inconsistencies. Individuals of varying language profiles may differ in their use and assessment of such words, and this can generate debate over whether there is redundancy in the way the bilingual mind maps like lexical items.

\section{RESEARCH QUESTIONS AND HYPOTHESES}

This study addresses the effect cognates could potentially have on lexical access in highly proficient English-Spanish and Spanish-English bilinguals 
through the analysis of data gathered from two distinct language tasks including the production and acceptability judgment of lexical representations. The purpose is to examine the possibility of cross-linguistic influence in both L1 to L2 and L2 to L1 of these two languages, and the guiding research questions of this study are as follows:

1. What is the nature of cognate effect in highly proficient English-Spanish/Spanish-English bilinguals in spontaneous English speech production from an L1 to L2 versus an L2 to L1 approach?

2. What is the nature of the way highly proficient English-Spanish/ Spanish-English bilinguals assess cognate lexical items in English compared to their monolingual counterparts?

3. What is the nature of the way English-Spanish/Spanish-English bilinguals both produce and assess true, partial, and false cognates?

In addressing the first research question, it was predicted that bilinguals would demonstrate involvement (i.e. cognate effect) between both languages during the eliciting speech production task. This would be evidenced through proportionately higher employment of cognate words of English and Spanish when word frequency would dictate the likelihood of an alternative word choice in the target language. Further, it was expected that greater cognate effect would be found in the Spanish-English group working in their non-dominant language (English), as per the Revised Hierarchical Model (RHM) (Kroll \& Stewart, 1994) which asserts that "word-to-concept" mapping is stronger in the dominant language.

For the second research question, greater acceptance of problematic lexical representations from the bilinguals compared to their monolingual counterparts was expected, suggesting that language experience and use informs conceptualization of lexical items. The hypothesis was that the Spanish-dominant group would display the highest level of acceptability, again as per the RHM, followed by the English-dominant group, and then the monolinguals.

As for the third research question, it was hypothesized that there would be no significant difference between the way the bilingual groups would judge partial cognates but that they would accept them at a higher rate than the monolinguals. However, it was expected that the Spanish-dominant 
group, working in their L2, would judge false cognates to be more acceptable than either the English-dominant group or monolinguals, but that the English-dominant group would still accept false cognates more liberally than the monolinguals, given their language experience.

\section{THEORETICAL BACKGROUND}

\section{Cognate effect}

Cognates have been widely studied across a number of linguistic disciplines, as they represent overlap between two or more languages, as demonstrated in the introductory examples. Lemhöfer, Dijkstra, and Michel (2004) explain why cognates are so frequently and instrumentally used in exploring the mental lexicon, stating, "Because they represent the lexical overlap between languages, they offer a straightforward way to tackle the question whether even in a language-exclusive setting, bilinguals are influenced by their other language" (p. 587). This influence, or cognate effect, has been shown to manifest itself in a number of different ways and has been examined in several different linguistic sub-fields, including psycholinguistic research in association and decision tasks in bilinguals (Yudes, Macizo \& Bajo, 2010), word recognition in bilinguals (Dijkstra, Van Hell, \& Brenders, 2014) and trilinguals (Lemhöfer, et al., 2004), word recognition and acquisition (de Groot, Borgwaldt, Bos, \& van den Eijnden, 2002; Midgley, Holcomb, \& Grainger, 2011; Miller \& Farr, 1939). Greater speed and accuracy have been shown in naming cognates rather than non-cognate items (Lemhöfer, et al., 2004) and even when task requirements included only participants' dominant language (Van Hell \& Dijkstra, 2002). Further evidence for cognate effect has been advanced in studies on voice onset times in Spanish-English bilinguals of varying proficiencies (Amengual, 2012), citing more English-like pronunciation in the Spanish production of cognates, i.e. phonetic interference with higher proficiency.

Cognates and non-cognates have also been an integral part of examining the processes of lexical decision, which is, generally, how quickly one can discern cognates and non-cognates. Priming effects of cognate translations have been shown to demonstrate repetition in cognates as opposed 
to non-cognates (Sánchez-Casas, Davis \& Garcia-Albea, 1992), and interference from lexical neighbours and "meaning-related pairs" in translation equivalent recognition testing has also been shown (Sunderman \& Kro$11,2006)$. Other studies on lexical decision in monolinguals and bilinguals involving cognate effect include: Costa, 2005; Costa, Miozzo \& Caramazza, 1999; Costa \& Santesteban, 2004, among others. These studies demonstrate how two (or more) mental lexicons may be stimulated at one time within different processes of language processing. The process of inhibitory control (a process which effectively blocks a non-target language, theorized to occur at less proficient levels of language use - see Schwieter \& Sunderman, 2008; Schwieter \& Sunderman, 2011; Schwieter, 2013), and language-specific mechanisms models (Schwieter \& Sunderman, 2008) have been explored, but research is nowhere near conclusive in this area (Finkbeiner, Almeida, Janssen \& Caramazza, 2006). While results are not completely consistent, cognates have served as a useful tool for investigating cross-linguistic influence, and considerable headway has been made in this area of linguistics. In spite of on-going debate on a number of issues, consensus seems to be drawing closer to cascaded, non-selective models that support concurrent language activation in individuals proficient in more than one language. A discussion on the progression of these models in support of this and how they tie into cognate effect in lexical access will follow.

\section{Models of language processing and lexical access}

"The biggest challenge for a model of the bilingual lexicon in general is that it should account both for cross-language effects and the ability of bilinguals to use one language at a time" (Sherkina, 2003, p. 139). Indeed, explaining bilingual language processing is a complicated undertaking. However, several different models of language processing have been put forth, and many of them account for this persistent cognate effect. What is more important to the present study is that some of the modelling can account for multiple manifestations of single lexical items, suggesting that conceptual overlapping, like what we see in cognates (including partial cognates), can be reconciled. These models include those in support 
of integrated lexical storage and non-selective access, as well as those that can account for individual, experiential variables of language users.

In terms of lexical access, it is generally agreed that there are two stages of processing: the conceptualization of the semantic/syntactic lexical representation, i.e.lemma, and then the selection of its corresponding phonetic representation, i.e. lexeme, as per the Dual Stage Access Model (Caramazza, 1997). Though it is described in binary terms in this model, it is a truly nuanced process. Both "selective" (meaning not simultaneously activated) and "non-selective" (meaning simultaneously activated) models have been put forth, but there is still controversy over whether one lexicon may ever be selected for discretely (see Costa, Heij, \& Navarrete, 2006), or whether more than one language is always activated as per the Non-Selective Access Hypothesis (Lemhöfer, et al., 2004; Morsella \& Miozzo, 2002). The latter, non-selective access, has come to be more accepted as a result of more sophisticated research in cognitive processing (Van Hell and Dijkstra, 2002), and as a result of a number of other studies supporting this theory (Cuppini, Magosso, \& Ursino, 2013; de Groot, Delmaar, \& Lupker, 2000; Dunlap, Chen, Zhou, \& Yang, 2010, among others). There have been studies suggesting selective access (i.e. no influence from the non-target language), but it has been speculated that proficiency may have been too low in the participants (Van Hell \& Dijkstra, 2002), and Dijkstra et al. (2014) warn that null cognate effect findings in behavioural data does not necessarily mean that there is no cognitive effect. Kroll and de Groot (2005) compare language selection to register selection arguing that just as monolinguals do not select for formal language versus slang or "taboo words" there is no need for bilinguals to select for words of a particular language (p. 305). In this view, all language users are basically the same. Having access to another mental dictionary (mental lexicon) through knowledge of a second language is no different from having access to different variations of one single language. This notion is supported by many other scholars (Antoniou, Best, Tyler \& Kroos, 2010; de Bot \& Jaensch, 2015), who call for a more integrated approach to language processing, treating all languages as collective entities rather than separate ones in the brain.

In addition to a non-selective view, addressing how users of two or more lexicons with overlapping lexical representations (i.e. cognates) can 
function in one independent, target language has led to debate over either separate or integrated lexical storage of lexical representations. According to Kroll and de Groot (2005), "It is generally assumed that, during conceptual processing, not only the semantic representation of the intended concept but also those representations of semantically related concepts are activated to some degree" (p. 309). This remark is important to the current study because it means that in language production, conceptual processing also involves discerning between related concepts (i.e. cognates) before moving on to the next step: lexical selection. Basically, the lexicon of one language is not completely separate from another within this conceptualization stage. If this is true, then it would make sense for a highly proficient bilingual to produce and/or accept lexical representations with unclear conceptual boundaries (like those in partial cognates) in a way that monolinguals simply could not. This idea of semantically related concepts and how they are stored/accessed is supported by a number of models. The One-Store Hypothesis advocates for a single, integrated memory system of lexical representation, the Two-Store Hypothesis posits a separate system, and the Three-Store Hypothesis suggests that two or more languages are "differentially connected" in one "conceptual-experiential information store" (Szubko-Sitarek, 2015, pp. 67-68). Another well-known model in support of the integrated viewpoint is the Bilingual Interactive Activation + (BIA+) Model (Dijkstra \&Van Heuven, 2002), successor to the original BIA Model (Dijkstra \&Van Heuven, 1998). While this model is not able to account for language development (Basnight-Brown, 2014), it features an integrated word identification system with language nodes utilized to specify which language a lexical item belongs to and that word recognition is only somewhat influenced by language membership. However, different types of studies have produced results supporting each of these hypotheses. In particular, the integrationist view of lexical representation has been supported by studies citing cross-linguistic influence (Szubko-Sitarek, 2015). However, Sherkina (2003) points out that in the cognitive processing of cognates, conceptual representation and sound inventories do not necessarily come from single lexical nodes, but some processing models (i.e. the BIA+ Model) assume this, proving problematic. 
In addition to the aforementioned, static models of lexical storage and access, there is increasing support for the view that language processing and lexical representation may be more fluid, dependent on individual variables (Dijkstra \& van Heuven, 2002). This means we should consider how acts of "knowing, learning and using an additional language can interact with lexical access (Altarriba \& Heredia, 2014, p.9). For example, Cuppini, et al. (2013) suggest that higher language proficiency results in greater similarity in semantic systems, meaning that interlingual relationship systems may change over time, and, consequently, that individual language users' processing may be more dynamic than what the aforementioned models account for. This is supported in the previously mentioned RHM and L1 to L2 connections and echoed by Szubko-Sitarek (2015) stating that "with the increasing proficiency, stronger and stronger semantic links between concepts and L2 items are developed" (p.79). Something important to highlight here is that these are non-selective, integrated, proficiency-based theories but that the RHM still presents a scenario whereby there are two separate lexicons. As a result, Desmet and Duyck (2007) proposed another revision of the RHM, one that depicted one lexicon with an independent semantic store. These models do account for the way in which lexical items may be conceived of and produced, but there are always individual differences in how words are conceptualized, selected for. To explain this, while also taking individual variability into account, we turn to usage-based, exemplar theory models. According to Bybee (2013) citing her Usage-Based Theory from 1985, "representations are strengthened by repetition, making them easier to access" (p. 59). Bybee (2001) plainly states, "Experience affects representation" (p. 6). These concepts of repetition and experience are fundamental to how individuals access lexical resources and may be applied to L1, L2, or Ln users. How this applies to an understanding of lexical representation in bilinguals may be further understood by Exemplar Theory. According to Gahl and Yu (2006), redundancy in mental representations is central to exemplar models in linguistic theory, meaning lexical representations are neither conceptualized nor selected for in isolation. Exploring Exemplar Theory and the lexical/phonetic interface, Amengual (2012) suggests that "all the possible phonetic manifestations and lexical mean- 
ings are stored with each unit (word), in addition to different contextual variations and realizations" and that each lexical item "is stored with redundant phonetic, semantic, and contextual information represented in memory by a "cloud" of remembered exemplars which directly reflect a speaker's experience with the specific word in both production and perception" (p. 527). This means that semantically overlapping lexical items are concurrently activated, stored together, not in isolation, and that one particular user may store different items differently as per experience and usage. This and the other models in support of integrated lexical storage and non-selective access, as well as those that can account for individual, experiential variables of language users can account for multiple manifestations of single lexical items, suggesting that conceptual overlapping, like what we see in cognates (including partial cognates) and cross-linguistic influence can be better understood.

\section{METHOD}

This study is comprised of two tasks, both carried out with participants placed in a single-language context (Green \& Abutalebi, 2013) whereby only the use of English was requested. In the first task, participants were asked to spontaneously produce English synonyms to a list of 45 English words. The task was carried out verbally, and participants were not shown the transcribed list of words, so that there would be no visual/orthographic priming effect (Van Hell \& De Groot, 2008). Words in Task 1 were presented in isolation, without the benefit of being embedded within a larger matrix sentence for semantic priming, and the participants were asked to respond one at a time. Responses were audio recorded in order to elicit natural, immediate responses, in lieu of formal time constraint, as to avoid "strategizing" (Szubko-Sitarek, 2015, p. 166).

Target words were selected based on known synonyms with cognateness between English and Spanish, and filler control words were also included. Word forms included verbs, adjectives and nouns. For example, some of the words included were: to reply, friendly, and environment. A cognate synonym for these examples would include: to respond, amicable, 
and ambiance. Fillers with no intended cognate relationship between English and Spanish such as to wash, goofy, and dream were also included to serve as control words. Whether the participants would more often produce these cognate synonyms in spite of their being less frequently used English words, or whether they would produce entirely dissimilar items was of interest here. The idea was that uttering less frequent cognate synonyms would demonstrate possible effect from the non-target language (Spanish). The completed list can be found in Appendix A.

In the second task, participants were asked to rate their level of acceptability on a scale of 1-5 of 60 sentences, listed in full in Appendix B, containing four different types of variables: cognates, preposed adjectives, preposed adverbs and inverted noun clauses. As the focus of this study is cognate effect, only the cognate/semantically overlapping tokens will be analyzed and discussed here. These include partial and false cognates, as described in the introduction of this paper. The scale markers were defined as follows:

1. Unacceptable; meaning is completely unclear; I would never express myself in this way.

2. Somewhat unacceptable; meaning is somewhat unclear; I am unlikely to express myself in this way.

3. Satisfactory; I probably wouldn't say it this way, but I understand the meaning just fine.

4. Somewhat acceptable; meaning is somewhat clear; I might express myself in this way.

5. Acceptable; meaning is completely clear; I would most likely express myself in this way.

For both types of cognates (partial and false), there was always a paired equivalent sentence featuring an alternative, standard word in place of the partial/false cognate. It is important to note that the sentence pairs in Task 2 were not presented together. All 6o sentences were randomized, so participants were not asked to compare pairs beside one another, but rather assess them one at a time, in no particular order. This first pair exemplifies the partial cognate presented in 1a., and its more standard or correct synonym introduced in $1 b$. 
(1) a. The professor presented herself to the class on the first day.

b. The professor introduced herself to the class on the first day.

While the meaning of present in this context is very similar to that of introduce, $1 \mathrm{~b}$. is the more standard choice. This next pair exemplifies the false cognate gracious in $2 \mathrm{a}$ and the more appropriate word choice funny in $2 b$.

(2) a. My mom is always telling jokes; she is so gracious.

b. My mom is always telling jokes; she is so funny.

Pairs like these were included among the total 60 sentences, and like Task 1, participants were asked to respond without hesitation, rating each sentence based on their first impression. Unlike Task 1, participants were able to see and read the target sentences, so they did have the benefit of both sentence context and visual (orthographic) cues to make their acceptability judgments.

This study features 36 participants in three participant groups with a ratio of 23 females to 13 males. A number of adult, highly proficient English-Spanish $(n=12)$ bilinguals, highly proficient Spanish-English $(n=12)$ bilinguals, and monolingual Anglophones $(n=12)$ were invited to carry out two tasks with all interaction/instructions spoken in English. Prior to testing, participants were asked to fill out a detailed language proficiency background questionnaire citing, among other details: the age they began to learn their L2, hours of L2 use per week, self-reported proficiency and the level of importance their L2 holds for them. A number of the English-Spanish bilinguals cited some formal schooling in French but expressed superior proficiency in and much more frequent use of Spanish, which was important to this study. Table 1 summarizes the key information gathered through this questionnaire (Table 1).

As seen in Table 1, the first group consisted of all late English-Spanish bilinguals raised in English-speaking Canadian/American homes with an average age of Spanish onset of 16.7. The third group, the control group, consisted of all monolingual, Anglophone individuals ranging in age from young adult to early senior, who, in spite of some reported French language schooling as part of mandatory Ontario French curriculum as children, cited zero contact with French language and minimal to no ability 


\section{Table 1. Bilingual background information}

\begin{tabular}{|c|c|c|c|c|}
\hline Participant & $\begin{array}{c}\text { Average } \\
\text { Group }\end{array}$ & $\begin{array}{c}\text { Self-Reported } \\
\text { of L2 Onset } \\
\text { Weekly Use } \\
\text { of L2 (in } \\
\text { hours) } \\
\mathbf{M}(\mathrm{SD})\end{array}$ & $\begin{array}{c}\text { Importance } \\
\text { proficiency } \\
\text { 1=None; 6=Native } \\
\mathbf{M}(\mathrm{SD})\end{array}$ & $\begin{array}{c}\text { 1=None; } \\
\text { 10=Utmost } \\
\mathbf{M}(\mathrm{SD})\end{array}$ \\
\hline English-Spanish & $16.7(8.1)$ & $12.1(12.2)$ & $4.3(0.5)$ & $9.3(1.1)$ \\
\hline Spanish-English & $15.0(7.5)$ & $30.3(15.8)$ & $4.1(0.7)$ & $9.7(0.7)$ \\
\hline
\end{tabular}

Note. All members of this group reported active, weekly use of Spanish (in spite of living in English-speaking countries), high or near-native proficiency in Spanish and rated Spanish as being of great importance in their lives. The second target group consisted of all late SpanishEnglish bilinguals with an average age of English onset of 15.0 who were formally trained in English as a second language and who were raised in Spanish-speaking countries in Spanishspeaking homes but who are all currently living in English-speaking Canada, with the exception of one who now resides in the United States. All members of this group reported consistent and regular use of both languages on a weekly basis.

to communicate in any language other than English. All participants had attained some level of post-secondary schooling, and, with the exception of four, all cited possession of at least some level of university education; those four had completed alternative post-secondary schooling. Those who cited university studies had successfully graduated or are currently in the process of doing so, and a number of them had already completed or are currently pursuing post-graduate studies.

\section{RESULTS}

The descriptive analysis for Task 1 revealed interesting findings between both the bilinguals as a whole and the monolingual control group, and between the two bilingual groups themselves. Figure 1 reveals the overall averages of cognates produced by each group, for each part of speech (verbs, adjectives and nouns), showing that there was a comparable rate of cognate effect in both bilingual groups.

Participants from the English-dominant group produced the highest average of cognate words across all three categories and across all three 


\section{Figure 1. Task 1: Overall cognate averages produced for each part of speech, per group in percentages}

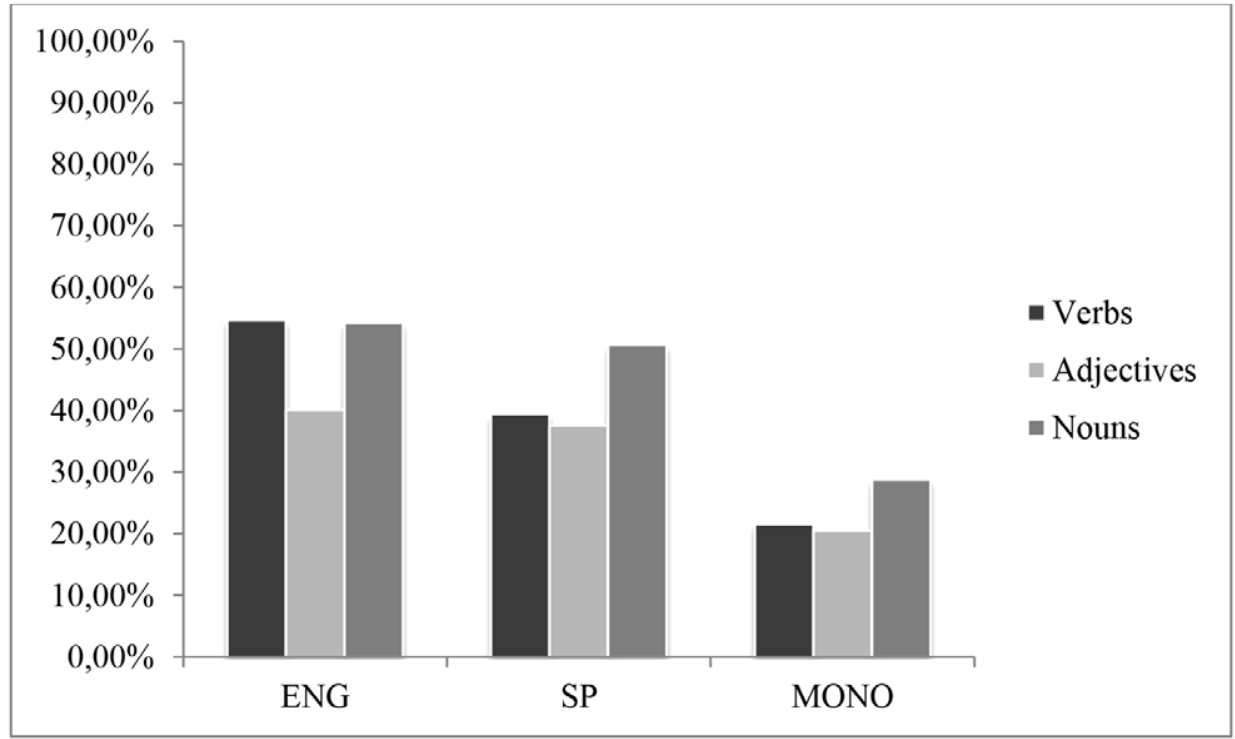

groups with an overall mean of $49.7 \%(\mathrm{sd}=0.31)$. Within the verbs category specifically, the English-dominant group produced a mean of $54.71 \%$ $(\mathrm{sd}=0.3)$ and almost an equal number of cognates within the noun category with a mean of $54.24 \%$ ( $\mathrm{sd}=0.37$ ), and within the adjectives category, they produced an average cognate mean of $40.15 \%(\mathrm{sd}=0.25)$. While the Spanish-dominant group also produced a considerable number of cognate items, the overall average was significantly lower than that of the English-dominant group with an overall mean of $42.52 \%(s d=0.29)$. Within this group, the category that revealed the most cognate words was the nouns category (mean $=50.63 \%$, sd $=0.31$ ), which is comparable to the mean produced by the English-dominant group. Within the verbs and adjectives categories, however, the average number of cognates was $39.39 \%(\mathrm{sd}=0.31$ ) and $37.55 \%$ (sd $=0.25$ ), respectively. Calculating the average number of cognates produced from both bilingual groups, the overall resulting mean is $46.11 \%$ ( $\mathrm{sd}=0.3$ ) in contrast to the overall mean of $23.62 \%$ ( $\mathrm{sd}=0.2$ ) produced by the monolingual group. Like the Spanish-dominant group, the monolinguals produced the highest number of cognates within the nouns category $(m=28.79 \%$, 
$\mathrm{sd}=0.23$ ). The second highest percentage of cognate words came from the adjective category $(m=20.52 \%$, sd $=0.21)$ for the monolinguals, and within the verbs category the mean was $21.57 \%$ ( $\mathrm{sd}=0.17$ ).

Figure 2, Figure 3, and Figure 4 provide breakdowns of overall cognate averages and cognate responses per prompt word for each group: verbs, adjectives, and nouns, respectively.

In many cases, higher cognate rates are seen in bilinguals for the same prompt, demonstrating a similar nature of cognate effect. In order to examine this effect more carefully, however, it is necessary to reference word frequencies within the English language used in Canada in order to see whether or not the lexical items produced by the participants represent words that are simply just more frequently used, or whether they are less frequent words, and in the case of the bilinguals, selected for as a result of cognate effect coming from the non-target language. A complete list of the most frequently produced lexical items from Task 1 as compared to English word frequencies can be seen in Table 2. The "Prompts" column on the left hand side lists the words for which participants were asked to

Figure 2. Verb cognates produced for each prompt, per group, in percentages

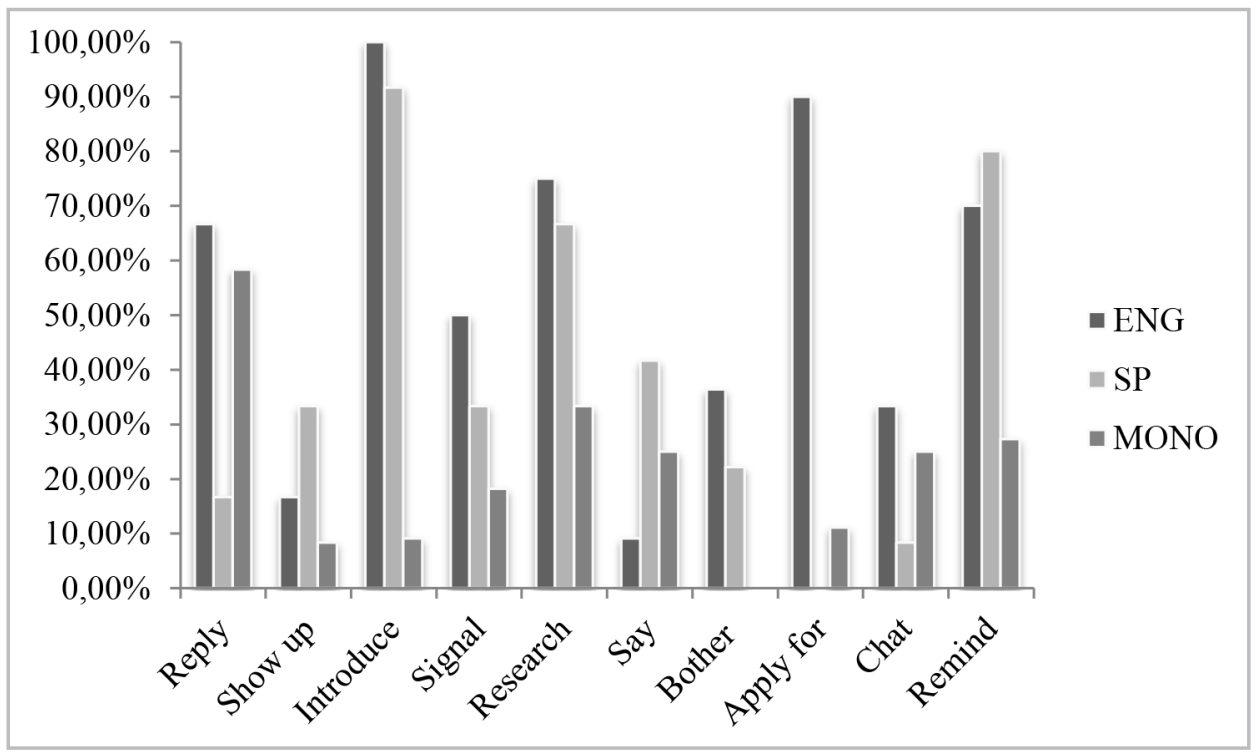


Figure 3. Task 1: Adjective cognates produced for each prompt, per word, per group, in percentages (\%)

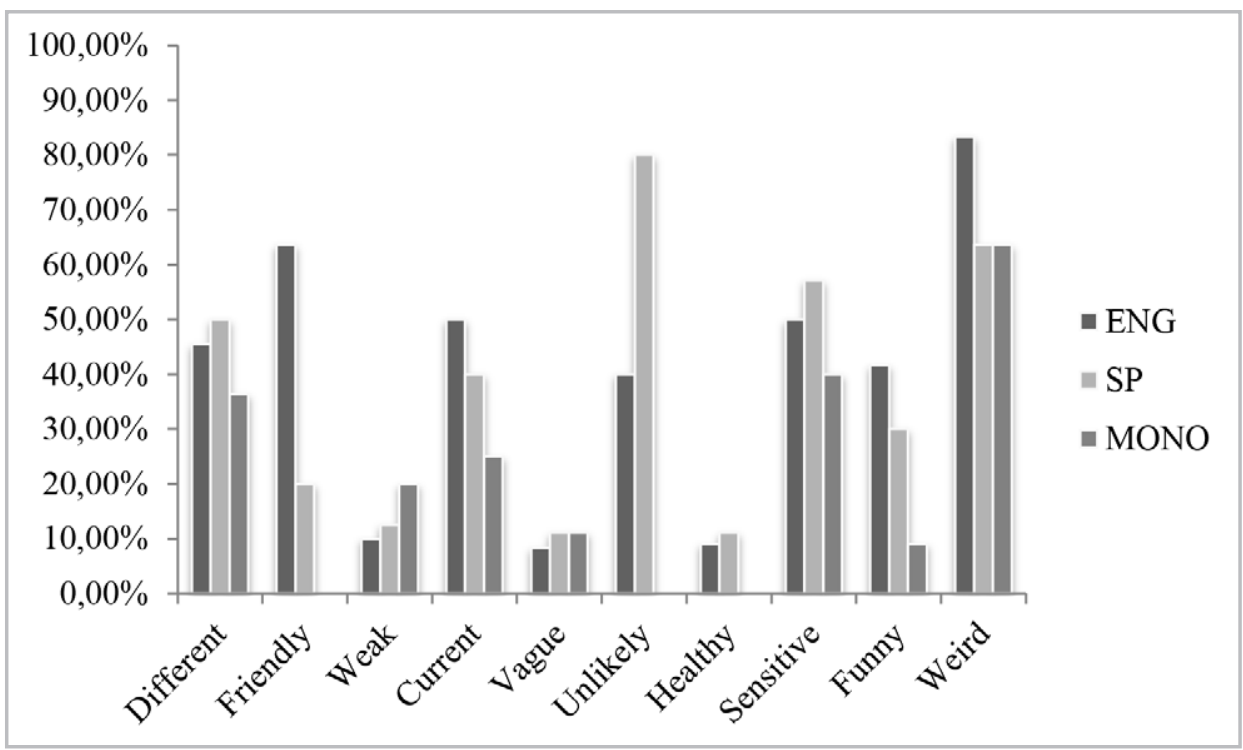

Figure 4. Task 1: Noun cognates produced for each prompt, per word, per group, in percentages (\%)

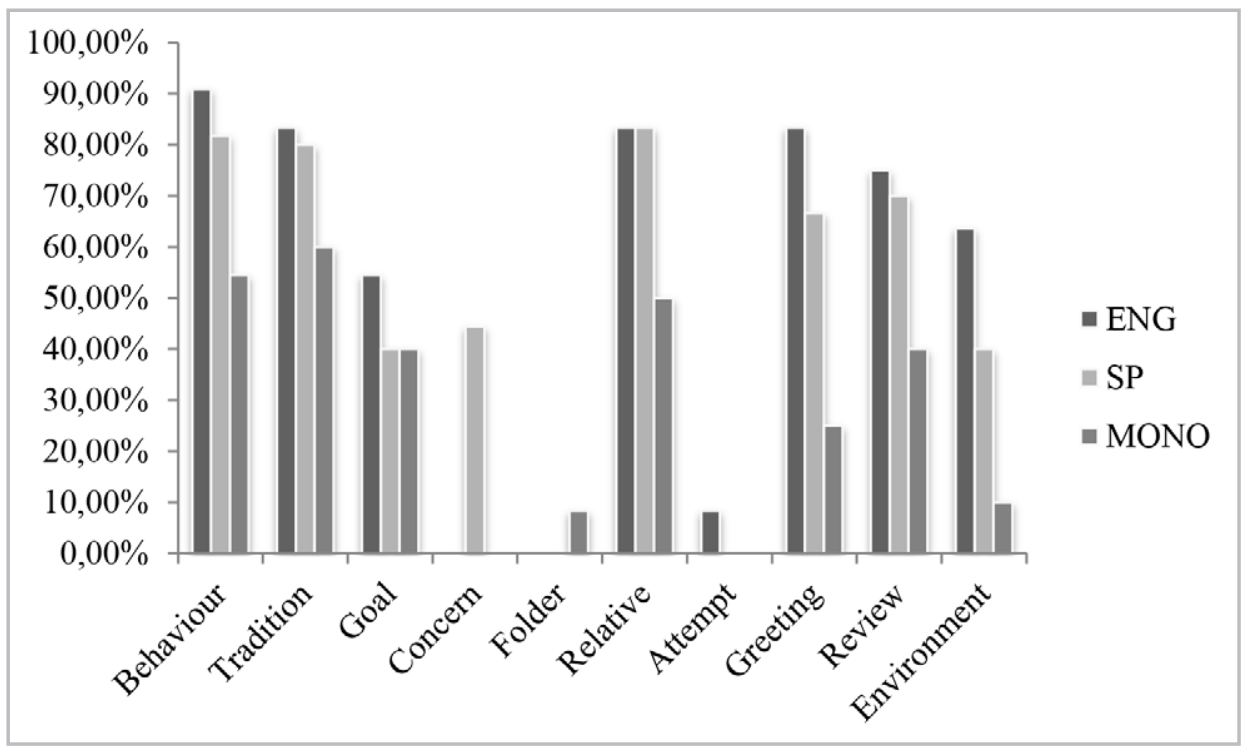


spontaneously provide synonyms, and the most frequent responses by each of the three test groups are provided. The "Freq" columns indicate how frequently each word appears in the Corpus of Canadian English (Strathy) (n.d.) of 50 million words. The higher the number, the more frequent the word.

\section{Table 2. Most frequent word responses in Task 1 and Canadian English word frequencies}

\begin{tabular}{|c|c|c|c|c|c|c|c|}
\hline $\begin{array}{l}\ddot{0} \\
\text { 芯 } \\
\text { م. } \\
\text { ڤ. }\end{array}$ & 怠 & 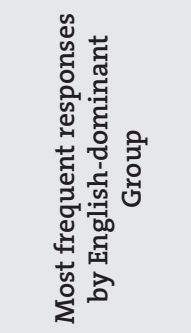 & 总 & 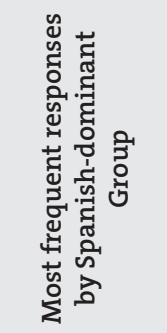 & 总 & 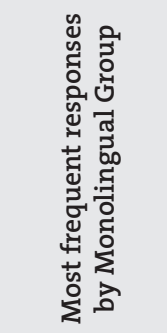 & 总 \\
\hline Reply & 226 & Respond & 2722 & Answer & 2997 & Respond & 2722 \\
\hline Show up & 485 & Arrive & 1266 & Appear & 5149 & Arrive & 1266 \\
\hline Introduce & 1608 & Present & 1704 & Present & 1704 & Greet & 181 \\
\hline Signal & 328 & Indicate & 3283 & Show & 10053 & Sign & 1454 \\
\hline Research & 3032 & Investigate & 1310 & Investigate & 1310 & Study & 2744 \\
\hline Say & 31875 & Speak & 5660 & Speak & 5660 & Speak & 5660 \\
\hline Bother & 537 & Annoy & 39 & Annoy & 39 & Annoy & 39 \\
\hline Apply for & 426 & Solicit & 138 & Submit & 1021 & Submit & 1021 \\
\hline Chat & 212 & Talk & 6517 & Talk & 6517 & Talk & 6517 \\
\hline Remind & 694 & Remember & 5793 & Remember & 5793 & Repeat & 1295 \\
\hline Different & 22361 & Distinct & 2112 & Distinct & 2112 & Opposite & 876 \\
\hline Friendly & 1137 & Amicable & 34 & Nice & 2556 & Kind & 624 \\
\hline Weak & 1723 & Not strong & 60 & Soft/Tired & 1726 & Feeble & 118 \\
\hline Current & 10282 & Actual & 3371 & Up-to-date & 228 & New/Now & 55900 \\
\hline Vague & 547 & Unclear & 1327 & Not clear & 562 & N/A & \\
\hline Unlikely & 1586 & Improbable & 117 & Different & 22361 & Uncommon & 408 \\
\hline Healthy & 3234 & Strong & 8657 & Good shape & 99 & Fit & 1451 \\
\hline Sensitive & 1886 & Sensible & 443 & $\begin{array}{l}\text { Emotional/ } \\
\text { Sensible }\end{array}$ & 1456 & Emotional & 2468 \\
\hline Funny & 1015 & Comical & 46 & N/A & & Hilarious & 110 \\
\hline Weird & 324 & Strange & 2013 & Strange & 2013 & Strange & 2013 \\
\hline Behaviour & 4305 & Comportment & 6 & Actions & 3148 & Actions & 3148 \\
\hline Tradition & 2923 & Custom & 699 & Culture & 8294 & Custom & 699 \\
\hline
\end{tabular}




\begin{tabular}{|c|c|c|c|c|c|c|c|}
\hline $\begin{array}{l}\ddot{0} \\
\text { 䓂 } \\
\text { o } \\
\text { 品 }\end{array}$ & 㥑 & 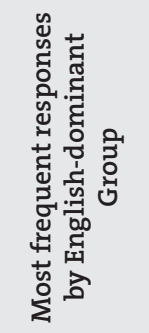 & 怠 & 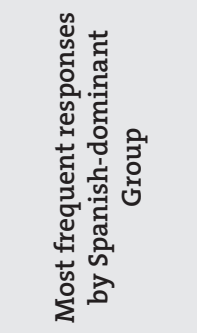 & 㥑 & 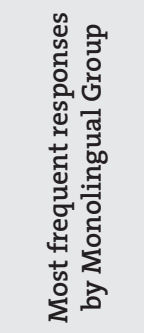 & 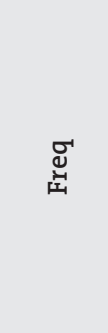 \\
\hline Goal & 6299 & Objective & 1651 & Objective & 1651 & Aim/Plan & 6489 \\
\hline Concern & 6192 & Worry & 235 & Preoccupation & 268 & Worry & 235 \\
\hline Folder & 53 & File & 1827 & File & 1827 & Binder & 259 \\
\hline Relative & 331 & Family & 21495 & Family & 21495 & Family & 21495 \\
\hline Attempt & 2925 & Try & 248 & Try & 248 & Try & 248 \\
\hline Greeting & 209 & Salutation & 10 & Salutation & 10 & Hello & 429 \\
\hline Review & 8220 & Revision & 542 & Revise & 196 & Check & 689 \\
\hline $\begin{array}{c}\text { Environ- } \\
\text { ment }\end{array}$ & 10044 & Ambiance & 35 & Context & 5642 & $\begin{array}{l}\text { Surround- } \\
\text { ings }\end{array}$ & 367 \\
\hline MEAN & 4167.3 & & $2445 \cdot 3$ & & 4005 & & 4170 \\
\hline SD & 6994 & & 4230 & & 5621 & & 10766.3 \\
\hline
\end{tabular}

As seen in the above table, the verb respond was given by the English-dominant group as a synonym to the verb reply most often ( $m=66.67 \%$ ). The synonym answer was provided in all other cases ( $m=33.33 \%)$. Citing the Corpus of Canadian English (Strathy) (n.d.), however, the verb answer appeared 2997 times in the 50-million-word corpus, or slightly more times than the verb respond appeared, which was 2722 times. When factoring in answer as a noun, however, its frequency almost triples, making it a highly common word within Canadian English. This suggests that the English-dominant bilinguals were choosing the less frequent English-Spanish cognate respond more often than the more frequent word in English answer. The Spanish-dominant groups had a near opposite effect, producing answer much more frequently as a synonym to reply ( $m=75.0 \%)$ with respond as a response only $17 \%$ of the time. Interestingly, the monolinguals also produced respond $(\mathrm{m}=58.3 \%)$ more frequently than answer $(\mathrm{m}=25 \%)$, so in this case it seems inconclusive whether or not the English-dominant bilinguals were influenced by their L2 Spanish lexicon or whether respond 
is just a popular synonym for reply. However, there is a marked difference with the responses to the verb research. Study appears in the Corpus of Canadian English (Strathy) (n.d.) 2744 times as a verb, while investigate appears only 1310 times. Interestingly, both bilingual groups more often provided investigate, which has a Spanish cognate, as a synonym, while not one monolingual produced that verb.

Another finding worth mentioning appeared in the nouns category. For behaviour, the word comportment was produced by the English-dominant group as a synonym $41.67 \%$ of the time, which was more often than any other response. Only $17 \%$ of the Spanish-dominant bilinguals produced this response, with quite a variety among the other responses. The monolingual group did not produce this word. The word comportment only appears in the Corpus of Canadian English (Strathy) (n.d.) 6 times out of 50 million words, suggesting that the English-dominant group may be influenced by their use of Spanish and the cognate comportamiento. Similarly, ambiance was produced by the English-dominant participants $33.33 \%$ of the time for the prompt environment. Spanish-dominant participants produced ambiance only one time (8\%), while this word was never produced by the monolinguals. Like comportment, ambiance appears rarely in the Corpus of Canadian English (Strathy) (n.d.), only 35 times. Thus, in many cases words with lower English frequency appeared with greater frequency among bilinguals, especially the English-dominant bilinguals, providing evidence for possible cognate effect, and an even greater effect in participants working within their dominant language. Furthermore, by calculating the average overall frequency of words produced by each group, the Spanish-dominant and Monolingual groups produced almost an identical rate of frequency, even though their specific word choices were different in many cases. The English-dominant participants produced a much lower average word frequency at 2445.3 per 50 million words compared to the other two groups producing close to double that in the 4000 words per 50 million range.

The responses from the number of items not listed in the relatively small size of each individual group. Analysis was carried out for the three individual groups on four different sentence types including sentences containing partial cognates, sentences containing false cognates, and sen- 
tences representing their "correct" respective pairings. Table 3 displays the between-group analyses for each sentence type, as indicated in the first column, and whether or not a significant effect was detected, indicated in the third column.

\section{Table 3. Task 2: Between-groups analyses per sentence type}

\begin{tabular}{|c|c|c|}
\hline Sentence Type & Group & $p$ value \\
\hline \multirow{4}{*}{ Partial Cognates (PCs) } & Eng-dominant-monolinguals & $(p=0.235)$ \\
\hline & Sp-dominant-monolinguals & $(p=0.082)$ \\
\hline & Eng-dominant-Sp-dominant & $(p=0.212)$ \\
\hline & Bilinguals - monolinguals & $(p=0.382)$ \\
\hline \multirow{4}{*}{ Corrected PCs } & Eng-dominant-monolinguals & $(p=0.006)$ \\
\hline & Sp-dominant-monolinguals & $(p=0.204)$ \\
\hline & Eng-dominant-Sp-dominant & $(p=0.024)$ \\
\hline & Bilinguals - monolinguals & $(p=0.032)$ \\
\hline \multirow{4}{*}{ False Cognates (FCs) } & Eng-dominant-monolinguals & $(p=0.22)$ \\
\hline & Sp-dominant-monolinguals & $(p=0.003)$ \\
\hline & Eng-dominant-Sp-dominant & $(p=0.079)$ \\
\hline & Bilinguals - monolinguals & $(p=0.024)$ \\
\hline \multirow{4}{*}{ Corrected FCs } & Eng-dominant-monolinguals & $(p=0.006)$ \\
\hline & Sp-dominant-monolinguals & $(p=0.438)$ \\
\hline & Eng-dominant-Sp-dominant & $(p=0.031)$ \\
\hline & Bilinguals - monolinguals & $(p=0.061)$ \\
\hline
\end{tabular}

As can be seen from Table 3, no significant effect was found between any group within the partial cognate sentences, except between the Spanish-dominant and monolingual groups $(p=0.08, u=57$ ), which was reaching significance $(d f=22)$. However, within the sentences containing correct lexical items in place of the partial cognates, there was significant effect between the English-dominant and monolingual groups ( $p=0.006, u=35.5$ ), between the Spanish-dominant and monolingual group $(p=0.02, u=46)$, and between the bilingual groups combined and the monolinguals $(p=0.032, u=102.5)(d f=34)$. No significant effect was found between the Spanish-dominant group and the monolinguals ( $p=0.2, u=68)$. 
Analysis of the groups and their judgments of the sentences containing false cognates also produced significant effect in some cases. Specifically, there was an effect found between the Spanish-dominant group and the monolinguals $(p=0.003, u=30)$, between the bilinguals as a whole and the monolinguals ( $p=0.02, u=98$ ), and analysis between the two bilingual groups showed a reaching significance effect $(p=0.08, u=56.5)$. There was no effect found for sentences with false cognates between the English-dominant and monolingual groups ( $p=0.22, u=69)$. The sentences containing correct lexical items in place of the false cognates also produced significant effect between some groups, namely between the Spanish-dominant and monolinguals groups ( $p=0.006, u=35)$ and between the two bilingual groups $(p=0.03, u=48)$. There was a nearly significant effect between the bilinguals as a whole and the monolinguals ( $p=0.06, u=112$ ), but no effect between the Spanish-dominant group and the monolinguals ( $p=0.44, u=81$ ).

Looking at the overall judgment means, using the 1-5 scale, the English-dominant group averaged $3.9(\mathrm{sd}=1.04)$, the Spanish-dominant group averaged 3.9 ( $\mathrm{sd}=0.79$ ) as well, and the monolinguals averaged $3.6(\mathrm{sd}=1.05)$. In all cases, each group judged the "correct" sentences to be more acceptable than those containing partial or cognate words, but as the statistical analysis (above) shows, there was significant variation throughout. The fact that there was greater statistical significance in the so-called "correct" sentences is of interest because, in theory, the native English speakers should have accepted them in a more similar way.

\section{DISCUSSION}

The results from Task 1 indicate that cognates were produced in greater numbers for the English-dominant group than the other two groups. This finding runs contrary to the original hypothesis, which predicted that there would be greater cognate effect from Spanish demonstrated within the Spanish-dominant group working in their L2. The original hypothesis was based on the RHM (Kroll and Stewart, 1994), which suggests that "word-to-concept" mapping is stronger in the dominant language, but the results here do not support that. A significant number of partial cognates 
(and even false cognates) were produced by the English-dominant bilingual group, suggesting that L2 interference seemed to be in effect. This is an interesting finding given that the English-dominant group was working within a native language interactional context. We do know that stronger semantic links are developed as proficiency increases (Van Hell \& Dijkstra, 2002), so this could account for these highly proficient English-dominant bilinguals being influenced by their L2. However, this does not account for the finding that Spanish cognate effect also appeared in the equally proficient Spanish-dominant English users. This latter group seemed to be highly influenced by frequently used words in English, which also suggests L2 influence, but their rates of Spanish cognate words (including false cognates) was still much higher than the monolinguals. This variability between the bilinguals points towards usage and exemplar models presented earlier which suggest that individual factors such as repetition and experience can impact how lexical representations may be conceptualized and, subsequently, produced. It is possible that these Spanish-dominant English bilinguals, living in an English-speaking environment, are more influenced in their L2 by the input they receive in their L2, rather than by their L1, but this contradicts the RHM in that it suggests the most dominant language should still prevail. It is important, however, to acknowledge the subjectivity within Task 1 and the selection of the target words. While they were selected for their known synonyms with cognateness between English and Spanish, a better approach may have been to precede the current study by following one of two previous methods: a similarity rating task (De Groot \& Nas, 1991), or a translation-elicitation task (Kroll \& Stewart, 1994) to assess the cognates beforehand. Unfortunately, such measures were not taken prior to carrying out the present study and were, therefore, not controlled for. A future replica of this study is needed to better confirm the current results with more careful attention to cognate designation. In spite of this, it is believed that the differences in production across the groups were significant enough to account for any potential margin of subjectivity.

The results from Task 2 also suggest that these independent groups are different in the way they negotiate lexical items, as partial cognates, 
false cognates and even perfectly standard, non-cognate lexical representations were judged differently. Interestingly, in comparing the results between the two tasks, the way cognates were produced and the way that they were perceived were different. While the production task showed the English-dominant group producing much higher rates of the different types of cognates as compared to their monolingual counterparts, the judgment task showed no significant difference in how these two groups perceived either partial or false cognates. This suggests that there was no statistically significant cognate effect in the English-dominant bilinguals, counter to prior research (Sherkina, 2003) claiming that there is always a cognate effect. More surprising still, is the fact that there was a significant effect in the way these two groups (both English natives) assessed the "correct" sentences. The reverse was true for the Spanish-dominant participants as compared to the monolinguals in the second task, as there was more significant effect found in the partial and false cognates than in the correct sentences. This suggests that these two groups differed in the way they judge cognates but not in the way they judged correct sentences, which means there was a cognate effect but that their L2 competency was strong enough to recognize correct sentences like a monolingual. This finding for the semantically overlapping partial and false cognate items supports the RHM and the idea that L1 conceptualization should dominate. This matches the Task 1 results in one way but not in another: the Spanish-dominant group may have been influenced by their L1 in terms of cognates in some measure, but not so in terms of how they assessed correct sentences. Such results suggest that language experience and usage may have given them an edge in production but not in interpretation.

The results from both tasks support previous work on cognate effect and cross-linguistic influence in part, but also support exemplar and usage-based theories. While it is not entirely conclusive, this provides further evidence for the notion that knowing more than one language interacts with the way lexical items are processed at least in some ways. The theoretical implications here are that languages may be activated concurrently in bilinguals, as per the non-selective models, and that selection of lexical items may be integrated whereby like concepts 
are associated in their use, but based on the findings in this study, it is not possible to speculate on where or how they are stored in the brain. However, the use of cognates in this study as a tool has allowed for some further exploration into semantic modulation at the conceptual level of lexical processing and has contributed to some further support for the idea that second language knowledge can influence dominant L1 performance. Finally, due to the variability found in the results, notwithstanding any inherent flaws to the study itself, some measure of individual language experience must be acknowledged in the way models of lexical processing are designed.

\section{CONCLUSION}

To conclude, this study has looked at cognate effect and lexical processing in highly proficient English-Spanish and Spanish-English bilinguals. It has been able to provide further evidence for cross-linguistic influence through cognate effect and discussion of lexical items both in production and in the way they are judged. While this study cannot account for all idiosyncrasies found within the analyses, it has demonstrated some clear differences in the performances of the three participant groups. English-dominant bilinguals demonstrated influence from their L2 in the production task but showed variation in the judgment task as compared to the other groups. This shows that at high levels of language competency, an L2 can influence and even interfere with dominant, native language production. The Spanish-dominant group seemed to demonstrate some influence from both their L1 and their L2 in that they produced a significant number of cognate words but also many highly frequently used English words; they also showed both L1 and L2 influence in the judgment task with significant differences between their judgments in partial and false cognates compared to the monolinguals. This suggests input and language context to be a powerful influence. The bilinguals combined generally showed an overall significant difference compared to the monolinguals, supporting the notion that knowledge of a foreign language does inform knowledge of a native language and vice versa. In particular, given the semantic overlapping of the lexical items featured in this study, it may be suggested that 
at the conceptual level of lexical processing, there is evidence for integrated storage of like lexical representations.

\section{REFERENCES}

Altarriba, J., \& Heredia, R. R. (2014). Introduction: Bilingual memory representation. In R. R. Heredia \& J. Altarriba (Eds.), Foundations of bilingual memory (pp. 3-10). New York, NY: Springer New York. doi:10.1007/978-1-4614-9218-4

Amengual, M. (2012). Interlingual influence in bilingual speech: Cognate status effect in a continuum of bilingualism. Bilingualism: Language and Cognition,15(3),1-14. doi:10.1017/S1366728911000460

Antoniou, M., Best, C. T., Tyler, M. D. \& Kroos, C. (2010). Language context elicits native-like stop voicing in early bilinguals' productions in both L1 and L2. Journal of Phonetics, 38, 640-653.

Basnight-Brown, D.M. (2014). Models of lexical access and bilingualism. In R. R. Heredia \& J. Altarriba (Eds.), Foundations of bilingual memory (pp. 85-107). New York, NY: Springer New York. doi:10.1007/9781-4614-9218-4

Caramazza, A. (1997). How many levels of processing are there in lexical access? Cognitive Neuropsychology, 14, 177-208.

Child, J. (2010). Introduction to Spanish translation ( $3^{\text {rd }}$ ed.). Lanham, MD: University Press of America.

Corpus of Canadian English (Strathy). (n.d.). [Data set]. Retrieved from http:// corpus.byu.edu/can/

Costa, A. (2005). Lexical access in bilingual production. In J. Kroll \& A. de Groot (Eds.), Handbook of bilingualism: Psycholinguistic approaches (pp. 308-325). New York, NY: Oxford University Press.

Costa, A., Heij, W. L. \& Navarrete, E. (2006). The dynamics of bilingual lexical access. Bilingualism: Language and Cognition, 9(2), 137-151. doi:10.1017/S1366728906002495

Costa, A., Miozzo, M. \& Caramazza, A. (1999). Lexical selection in bilinguals: Do words in bilingual's lexicon compete for selection? Journal of Memory and Language, 41, 365-397. 
Costa, A. \& Santesteban, M. (2004). Lexical access in bilingual speech production: Evidence from language switching in highly proficient bilinguals and L2 learners. Journal of Memory and Language, 50(4), 491-511. doi:10.1016/j.jml.2004.02.002

Cuppini, C., Magosso, E. \& Ursino, M. (2013). Learning the lexical aspects of a second language at different proficiencies: A neural computational study. Bilingualism:Language and Cognition,16(2),1-22. doi:10.1017/ S1366728911000617

de Bot, K. Cox, A., Ralston, S., Schaufeli, A., \& Weltens, B. (1995). Lexical processing in bilinguals. Second Language Research, 11(1), 1-19. doi:10.1177/026765839501100101

de Bot, K., \& Jaensch, C. (2015). What is special about L3 processing? Bilingualism: Language and Cognition, 18(2), 130-144.

Bybee, J. (2001). Phonology and language use. Cambridge, UK: Cambridge University Press.

Bybee, J. (2013). Usage-based theory and exemplar representations of constructions. In T. Hoffmann \& G. Trousdale (Eds.), The Oxford handbookof construction grammar, (pp.49-69).NewYork,NY:Oxford University Press. doi:10.1093/oxfordhb/9780195396683.013.0004

De Groot, A. M. B., Borgwaldt, S., Bos, M. \& van den Eijnden, E. (2002). Lexical decision and word naming in bilinguals: Language effects and task effects. Journal of Memory and Language, 47(1), 91-124.

De Groot, A. M. B., Delmaar, P. \& Lupker, S. J. (2000). The processing of interlexical homographs in translation recognition and lexical decision: Support for non-selective access to bilingual memory. The Quarterly Journal of Experimental Psychology Section A: Human Experimental Psychology, 53(2), 397-428. doi:10.1080/713755891

De Groot, A. M. B., \& Nas, G. L. J. (1991). Lexical representation of cognates and noncognates in compound bilinguals. Journal of Memory and Language, 30, 90-123.

Desmet, T., \& Duyck, W. (2007). Bilingual language processing. Language and Linguistics Compass, 1(3), 168-194. doi:10.1111/j.1749818X.2007.00008.x 
Dijkstra, T., Van Hell, J. G. \& Brenders, P. (2014). Sentence context effects in bilingual word recognition: Cognate status, sentence language, and semantic constraint. Bilingualism: Language and Cognition, 18(4), 1-17. doi:10.1017/S1366728914000388

Dijkstra, A. \& van Heuven, W. (1998). The BIA-model and bilingual word recognition. In J. Grainger \& A. Jacobs (Eds.), Localist connectionist approaches to human cognition (pp. 189-225). Mahwah, NJ: Erlbaum.

Dijkstra, A. \& van Heuven, W. J. B. (2002). The architecture of the bilingual word recognition system: From identification to decision. Bilingualism: Language and Cognition, 5, 175-197.

Dunlap, S., Chen, B., Zhou, H. \& Yang, M. (2010). Language nonselective access to phonological representations: Evidence from Chinese-English bilinguals. The Quarterly Journal of Experimental Psychology, 63(10), 2051-2066. doi:10.1080/17470211003718705

Finkbeiner, M., Almeida, J., Janssen, N. \& Caramazza, A. (2006). Lexical selection in bilingual speech production does not involve language suppression.Journal of Experimental Psychology: Learning, Memory, and Cognition, 32(5), 1075-1089. doi:10.1037/0278-7393.32.5.1075

Gahl, S., \& Yu, A. C. L. (2006). Introduction to the special issue on exemplarbased models in linguistics. The Linguistic Review, 23, 213-216.

Green, D., \& Abutalebi, J. (2013). Language controls in bilinguals: The adaptive control hypothesis. Journal of Cognitive Psychology, 25(5), 515-530. doi:10.1080/20445911.2013.796377

Johnston, M. C. (1941). Spanish-English cognates of high frequency. The Modern Language Journal, 25(5), 405-417. doi:10.1111/j.1540-4781.1941. tbo3031.x

Kroll, J. F. \& Stewart, E. (1994). Category interference in translation and picture naming: Evidence for asymmetric connections between bilingual memory representations. Journal of Memory and Language, 33, 149-174.

Lemhöfer, K., Dijkstra, A. \& Michel, M. (2004). Three languages, one ECHO: Cognate effects in trilingual word recognition. Language and Cognitive Processes, 19, 585-611. 
Midgley, K. J., Holcomb, P. J. \& Grainger, J. (2011). Effects of cognate status on word comprehension in second language learners: An ERP investigation. Journal of Cognitive Neuroscience, 23(7), 1634-1647. doi:10.1162/jocn.2010.21463

Miller, M. M. \& Farr, G. (1939). Student recognition of some SpanishEnglish cognates. The Modern Language Journal, 24(3), 216-220. doi:10.1111/j.1540-4781.1939.tbo29o2.x

Morsella, E. \& Miozzo, M. (2002). Evidence for a cascade model of lexical access in speech production. Journal of Experimental Psychology: Learning, Memory, and Cognition, 28(3), 555-563.

Sánchez-Casas, R., Davis, C., \& García-Albea, J. (1992). Bilingual lexical processing: Exploring the cognate-noncognate distinction. European Journal of Cognitive Psychology, 4, 293-310.

Schwieter, J. W. \& Sunderman, G. (2008). Language switching in bilingual speech production: In search of the language-specific selection mechanism. The Mental Lexicon, 3(2), 214-238.

Schwieter, J. \& Sunderman, G. (2011). Inhibitory control processes and lexical access in trilingual speech production. Linguistic Approaches to Bilingualism, 1(4), 391-412. doi10.1075/lab.1.4.02sch

Sherkina, M. (2003). The cognate facilitation effect in bilingual speech processing. Toronto Working Papers in Linguistics, 21, 135-151.

Schwieter, J. (2013). Lexical inhibition in trilingual speakers. In J.-M. Tirkkonen \& E. Anttikoski (Eds.), Proceedings of the $24^{\text {th }}$ Scandinavian Conference of Linguistics (pp. 249-260). Joensuu, Finland: University of Eastern Finland Press. Retrieved from http://urn.fi/ URN:ISBN:978-952-61-0924-4

Sunderman, G. \& Kroll, J. F. (2006). First language activation during second language lexical processing: An investigation of lexical form, meaning, and grammatical class. Studies in Second Language Acquisition, 28(3), 387-422. doi:10.1017/So272263106060177

Szubko-Sitarek, W. (2015). Multilingual lexical recognition in the mental lexicon of third language users. Berlin: Springer. doi:10.1007/9783-642-32194-8 
Van Hell, J. G. \& De Groot, A. M. B. (2008). Sentence context modulates visual word recognition and translation in bilinguals. Acta Psychologica, $128,431-451$.

Van Hell, J. G. \& Dijkstra, T. (2002). Foreign language knowledge can influence native language performance in exclusively native contexts. Psychonomic Bulletin and Review, 9, 780-789.

Yudes, C., Macizo, P. \& Bajo, T. (2010). Cognate effects in bilingual language comprehension tasks. Neuroreport, 21(7), 507-512. doi:10.1097/ WNR.obo13e328338bge1

\section{APPENDIX A}

Task 1: Participants will be asked to produce synonyms to the following list of 45 words (audio recorded with the permission of each participant) in order to elicit natural responses.

\section{Verbs:}

1. Show up

2. Introduce

3. Signal

4. Research

5. Say

6. Bother

7. Apply for

8. Chat

9. Remind

\section{Adjectives:}

10. Different

11. Friendly

12. Weak

13. Current

14. Vague 
15. Unlikely

16. Healthy

17. Sensitive

18. Funny

19. Weird

\section{Nouns:}

20. Behaviour

21. Tradition

22. Goal

23. Concern

24. Folder

25. Relative

26. Attempt

27. Greeting

28. Review

29. Environment

\section{(Fillers):}

30. Walk

31. Shout

32. Teach

33. Wash

34. Travel

35. Goofy

36. Understanding

37. Energetic

38. Cautious

39. Introverted

40. Exercise

41. Construction

42. Publication

43. Dream

44. Lounge 


\section{APPENDIX B}

Task 2: Participants will be asked to rate their level of acceptability of the following 60 sentences containing "grey" cognates, false cognates, preposed adverbs/adjectives and question order in embedded clauses.

1. Unacceptable; meaning is completely unclear;

I would never express myself in this way.

2. Somewhat unacceptable; meaning is somewhat unclear;

I am unlikely to express myself in this way.

3. Satisfactory; I probably wouldn't say it this way, but I understand the meaning just fine.

4. Somewhat acceptable; meaning is somewhat clear;

I might express myself in this way.

5. Acceptable; meaning is completely clear;

I would most likely express myself in this way.

1. What time did your friend appear at the party last night?

2. You have traveled a lot, so you know many different cultures.

3. I have an investigation due on Monday for my European History class.

4. We saw many distinct animals at the zoo on the weekend.

5. I would like to do a Master's degree, but I have to solicit a position in a program first.

6. The two friends sat in the coffee shop conversing for a few hours.

7. My best friend is such a comical person; She always makes me laugh.

8. I'm not sure how to get to your house by car, so you'll have to indicate for me.

9. If you have time, could you revise my grammar before I hand in this assignment?

10. Chocolate can make children demonstrate poor temperament. 
11. What time did your friend show up at the party last night?

12. You have traveled a lot, so you are familiar with many different cultures.

13. I have an essay due on Monday for my European History class.

14. We saw many different animals at the zoo on the weekend.

15. I would like to do a Master's degree, but I have to apply for a position in a program first.

16. The two friends sat in the coffee shop chatting for a few hours.

17. My best friend is such a funny person; She always makes me laugh.

18. I'm not sure how to get to your house by car, so you'll have to direct me.

19. If you have time, could you check my grammar before I hand in this assignment?

20. Chocolate can make children demonstrate poor behaviour.

21. The professor presented herself to the class on the first day.

22. The student gave a very lazy description of the experiment. It was too general.

23. Remember me to pick up the kids after school.

24. I didn't like that move because the storyline didn't have any sense.

25. If you don't assist all of the classes, you lose $10 \%$ in participation for the semester.

26. I'm preoccupied because I might not have enough money to pay for rent next month.

27. I didn't say him what happened because I didn't want him to get upset.

28. My new puppy is driving me crazy; I can't support his behaviour.

29. Part of my new job is to alphabetize all of the carpets for each of the clients.

30. My mom is always telling jokes; she is so gracious. 
31. The professor introduced herself to the class on the first day.

32. The student gave a very vague description of the experiment. It was too general.

33. Remind me to pick up the kids after school.

34. I didn't like that move because the storyline didn't make any sense.

35. If you don't attend all of the classes, you lose $10 \%$ in participation for the semester.

36. I'm worried because I might not have enough money to pay for rent next month.

37. I didn't tell him what happened because I didn't want him to get upset.

38. My new puppy is driving me crazy; I can't handle his behaviour.

39. Part of my new job is to alphabetize all of the folders for each of the clients.

40. My mom is always telling jokes; she is so funny.

41. We have to make more difficult this test

42. It's essential to write more clearly your ideas in your journal.

43. It is more interesting the novel than the movie version.

44. He more often eats vegetables than junk food.

45. You have to do more regularly the exercises in order to get in shape.

46. We have to make this test more difficult.

47. It's essential to write your ideas more clearly in your journal.

48. The novel is more interesting than the movie version.

49. He eats vegetables more often than junk food.

50. You have to do the exercises more regularly in order to get in shape.

51. We're not sure where is the hotel located.

52. Can you tell me why is there an extra charge on my credit card statement?

53. I wonder when is she coming. 
54. He is unaware of how much is the total of his cell phone bill.

55. Is it possible to find out who is the person serving us tonight?

56. We're not sure where the hotel is located.

57. Can you tell me why there is an extra charge on my credit card statement?

58. I wonder when she is coming.

59. He is unaware of how much the total of his cell phone bill is.

6o. Is it possible to find out who the person serving us tonight is? 